INTERNATIONAL JOURNAL OF RESEARCHES IN BIOSCIENCES, AGRICULTURE AND TECHNOLOGY (C) VISHWASHANTI MULTIPURPOSE SOCIETY (Global Peace Multipurpose Society) R. No. MH-659/13(N) www.vmsindia.org

\title{
ALLELOPATHIC EFFECTS OF FENCING PLANTS ON CROP PLANTS
}

\author{
P. S. Jadhav and V. S. Patil \\ L.B.S. College Satara,(Mharashtra, India) \\ jadhavprakash55@rediffmail.com
}

\begin{abstract}
:
Allelopathic effects of two fencing plants were studied on seed germination and sprounting of seedlings of jowar, wheat, bajara, gram, mung bean and cowpae. for this study $1 \%$ leaf extracts of Vitex negondo and Lantana camera were used. Percent germination as well as seedling growth of test crops was significantly lowered by the aqueous leaf extracts of fencing plants. While on an average jowar, bajara, wheat and gram were equally sensitive to toxic response. The extract of fencing plants significantly inhibited the seeding growth of jowar, bajara wheat, mungbean and cowpae while the extract was stimulatory to seedling growth of gram.
\end{abstract}

Keywords - Allelopathy, Vitex, Lantana,

\section{Introduction:}

Allelopathy as a natural phenomenon in plant - plant interaction plays an important role in agroecosystem. Rice (1984) defined allelopathy as ability of one plant to stimulate or inhibit the growth and development of neighbouring plants by secreting secondary compounds in to the environment.

Allelopathic effect is a complex and can involve the interaction of different classes of chemicals like phenolic compounds, flavonoids, terpenoids, alkaloids, steroids, and amino acids. With mixture of different compound sometimes having a greater allelopathic effect than individual compound these compounds are known as allelochemicales. Yamane(1992) have reported plant residues, leachates and root extracts can be the main source of allelochemicals. The plants selected for present work are Vitex negondo and Lantana camera which are used for fencing the crop field to protect crops from domastic and wild animals. In many parts of Maharashtra fencing plants have been reported by farmers to inhibit seedling growth in field crops and hence this study on allelopathic effect on crop plants was planed.

Jain et.al (1989)showed that leaf extract of Lantana camera cantains phenoic compounds , Protocatchuic acid,gentisic acid,P-hydrxy benzoic acid, ferulic acid, salicylic acid, Ocoumaric acid. Elakovich and Wooten (1996) state that dried leaf aqueous extract of vitex negondo contain P- hydroxy bezoic acid, Pcoumeric acid, furalic acid, vanillic acid, syrengic acid and 10 of flavonoids. The crops selected for the present study are pulse crops mungbeen (Vigana radiata) local, cowpea (Vigna catjunawalf) lacal gram (Cicer arietinum) local cereals jowar (Sorghum valgare peas) lacal shalu, bajara (Pennisetum typhoides berum)local and wheat (Triticum aestivum) Hd2189.
These crops are grown in many parts of Maharashtra (India) and hedged by the lantana and vitex. These fencing plants remain for many years on crop fields sides and their foliages are continuously add organic matter in soil of field sides hence efforts have been made to study allelopathic effects of fencing plants on crop plants the experiments were conducted to study the effect of aqueous extract of dried leaves of these fencing plants on the germination and seedling vigour of six test crops.

\section{Material and Methods:}

Allelopathic studay of two fencing plants was done on six major crops. To observe effect of leaf exract on germination of seed and seedling growth sheded senescent leaves of fencing plants lantana camera and vitex negundo were collected from the crop field sides. Collected leaves were washed with tap water to remove adhesiv soil particles and rewashed with distilled water and dried at $60^{\circ} \mathrm{c}$ for 24 hours in ovan. The dried leaves were finely powdered in electric grinder and used for preparation of extract. One gram of powder of senescent leaves of each plant was mixed separately in to $100 \mathrm{ml}$ sterilized distilled water in conical flask and kept for 24 hours. The solutions were then filtered through double layer muslin clouth. The filtrates were used as extract of $1 \%$ concentration for allelopathic studies. The extraction was done according to Nelson et. Al. (1960). Seeds of test crops cereals- jawars, bajara, and wheat, pulses -cowpea, gram and mungbean were obtained from seed lots of farmers. Seeds of crops were first treated with surface sterilent $0.1 \%$ mercuric chloride solution and repeatedly rinsed in distilled water. Sets of 20 seeds each were arranged for each crop. The germination studies were carried out by standered petriplate method. Surface sterilized seeds of test crops were placed in 
$10 \mathrm{~cm}$ dia petridishes autoclaved, lined with two filter papers and labeled, $5 \mathrm{ml}$ extract of each plant was used to moisten the paper in respective petridishes, $5 \mathrm{ml}$ distilled water was used to moisten the control set. These petridishes then kept in germinator at normal temperature After 48 hours incubation observation were made for germination percentage and result were recorded The emergence of radicle was considered as criterion for seed germination. The seedling growth (root and shoot length fresh and dry weight ) was recorded after 8 days of sowing. The seedling growth was determined from ten randomly selected seedlings per petridish and their mean values were recorded after measuring root and shoot length and fresh weight their biomss was dried in oven at $60^{\circ} \mathrm{c}$ overnight and dry weight was recorded.

\section{Results and Discussion:}

The purpose of this studay was to evaluate the effect of aqueous extract of vitex negondo and lantana camera on seed germination and seedling growth of jowar bajara, wheat, gram, mungbean and cowpea. To know the allelopathic effect $1 \%$ aqueous leaf extract of each fencing plant and control were used. Percent germination of test crop was significantaly lowered by the aqueous leaf extract of fencing plants while on an average jowar, bajara, wheat, gram were equally sensitive to toxic response of fencing plants and cowpea and mungbean germination was stimulated. The extract of vitex negondo significantly inhibited the seeding growth of jowar, bajara, wheat, mungbean while the extract was stimulatory to seedling growth of cowpea and gram. The extract was more inhibitory to root length as compared to shoot. In all test crops and dry weight significantaly reduced. The L. camera extract was stimulatory to gram seedling only. The extract was more inhibitory to seedling growth of jowar, bajara, mungbean and cowpea, dry weight of cereals was increased while in pulses dry weight was reduced.

Table. 1-Germination percentage of test crop seeds in $1 \%$ aqueous leaf extract of Fencing plants

\begin{tabular}{|l|l|l|l|}
\hline crop & $\begin{array}{l}\text { Control distilled } \\
\text { water germination } \\
\%\end{array}$ & $\begin{array}{l}1 \% \text { Extract of } \\
\text { Vitex } \\
\text { germination \% }\end{array}$ & $\begin{array}{l}1 \% \text { Extract of } \\
\text { Lantana } \\
\text { germination \% }\end{array}$ \\
\hline Jowar & 55.20 & 37.00 & 55.60 \\
\hline Wheat & 98.00 & 85.00 & 86.00 \\
\hline Bajara & 90.00 & 90.00 & 76.00 \\
\hline cowpea & 28.00 & 36.00 & 46.00 \\
\hline Mungbean & 38.00 & 53.00 & 46.00 \\
\hline Gram & 38.50 & 16.00 & 27.00 \\
\hline
\end{tabular}

Table. 2-Allelopathic effect of $1 \%$ leaf extract of Fencing plants on seedling growth of crop plants

\begin{tabular}{|c|c|c|c|c|c|c|c|c|c|c|c|c|}
\hline \multirow{3}{*}{$\begin{array}{l}\text { Crop } \\
\text { Jowar } \\
\end{array}$} & \multicolumn{4}{|c|}{ Control } & \multicolumn{4}{|c|}{$1 \%$ leaf extract of Vitex } & \multicolumn{4}{|c|}{$1 \%$ extract of Lantana } \\
\hline & \multicolumn{2}{|c|}{$\begin{array}{l}\text { Length in } \mathrm{cm} \\
\text { SL RL }\end{array}$} & \multicolumn{2}{|c|}{$\begin{array}{l}\text { Weigth in gm } \\
\text { FW DW }\end{array}$} & \multicolumn{2}{|c|}{$\begin{array}{l}\text { Length } \mathrm{cm} \\
\text { SL RL }\end{array}$} & \multicolumn{2}{|c|}{$\begin{array}{l}\text { Weigth in gm } \\
\text { FW DW }\end{array}$} & \multicolumn{2}{|c|}{$\begin{array}{l}\text { Length } \mathrm{cm} \\
\text { SL RL }\end{array}$} & \multicolumn{2}{|c|}{$\begin{array}{l}\text { Weigth in gm } \\
\text { FW DW }\end{array}$} \\
\hline & 3.72 & 2.17 & 0.42 & 0.074 & 1.01 & 1.63 & 0.29 & 0.088 & 1.98 & 0.98 & 0.28 & 0.091 \\
\hline Bajara & 3.74 & 4.24 & 0.275 & & 2.70 & 4.84 & 0.22 & 43 & 3.60 & 4.17 & 0.25 & 0.038 \\
\hline Wheat & 10.15 & 7.04 & o & & 6.95 & 4.96 & 0.625 & & 8.52 & 7.15 & 0.645 & \\
\hline Gram & 4.44 & 4.96 & 0.404 & & 4.58 & 6.11 & 0.35 & 0.136 & 4.58 & 5.41 & 0.350 & 0.138 \\
\hline Mungbear & 3.94 & 2.92 & 0.171 & 0.037 & 3.55 & 1.49 & 0.183 & 0.037 & 4.40 & 1.78 & 0.186. & 0.04 \\
\hline Cowpea & 7.16 & 5.29 & 0.326 & 0.08 & 4.15 & 4.83 & 0.148 & 0.067 & 4.78 & 3.69 & 0.279 & 0.072 \\
\hline
\end{tabular}

SL - Shoot length, RL- Root length, FW - Fresh W eight, DW - Dry weight

\section{References:}

Elakovich S.D and Wooten(1960) Allelopathic woody plants Part II:Mobea tarough Zelkova Allelopathy Journal 3(1):9-32

Jain R., Singh M.and Dejaman L.D. (1989) Qualitative and Quantitative characterization of phenolic compounds from Lantana camera leaves ,weed science 37:302-307

Nielson K.F ,Cuddy T.and Woods W (1960), The influence of the extract of some crops and soil residues on germination and growth, Canadian journal of plant science 40:188-197

Rice E.L.(1984) Allelopathy $2^{\text {nd }}$ ed.academic press Orlando FL.USA.

Yamane A. Nishimura H. and Mizutani J.(1992)

Allelopathy of yellow field Cress

(Rorippa sulvestris) Identification and characterization of phytotoxic constituents Journal of chemical ecology 28:259-267. 